\title{
Karyotype Variation in the Aphid Sitobion rosaeiformis (Das) (Homoptera: Aphididae)
}

\author{
D. C. Gautam and J. Dutta \\ Department of Biosciences, Himachal Pradesh University, Shimla, India
}

Accepted August 18, 1993

Aphids tend to show karyotype variations because of the presence of holocentric chromosomes and thelytokous mode of reproduction. Structural heterozygosity and variation in chromosome number within species have been reported in some aphid species (Blackman 1971, 1980, Chattopadhay et al. 1982, Brown and Blackman 1988, Blackman et al. 1990). These studies indicate that there is association between karyotypes and host plant in aphids. In this paper, karyotype variation in the aphid Sitobion rosaeiformis (Das) collected from Rosa sp. and Rubus ellipticus is reported.

\section{Materials and methods}

The populations of aphid Sitobion rosaeiformis (Das) (Subfamily-Aphidinae; TribeMacrosiphini) were collected from two different hosts Rosa sp. and Rubus ellipticus belonging to the family Rosaceae (Table 1). The collections were sent to CAB International Institute of Entomology, London for authentication and will be deposited in the Natural History Museum (BMNH) collection.

Apterous, viviparous female aphids were taken and chromosome squash preparations were made from young embryos dissected from these aphids. Fresh material was used in this study. Embryos were given pretreatment in $0.7 \%$ sodium citrate solution for $30 \mathrm{~min}$ and then fixed in a fresh mixture of 1:3 acetic ethanol. After 25 min embryos were transferred to a drop of $50 \%$ acetic acid on a glass slide. A coverslip was gently put on the material and it was then squashed, first by tapping and then by applying thumb pressure. Coverslips were dislodged off the slides with a sudden jerk. The slides and coverslips were dried and stained with $2 \%$ Giemsa stain at pH 6.8 .

The diploid chromosome number was counted in 50 well spread metaphase plates and ten best plates were selected for chromosomal measurements. Chromosomes of almost equal lengths were assumed to be homologous pairs and the relative length of each pair was calculated for constructing idiograms. Photomicrographs of well spread metaphase plates were taken at a magnification of $\times 2000$.

Table 1. Collection data and diploid chromosome number $(2 n)$ of different populations of Sitobion rosaeiformis (Das)

\begin{tabular}{lccccccc}
\hline \hline Host plant & $\begin{array}{c}\text { Date of } \\
\text { collection }\end{array}$ & $\begin{array}{c}\text { Site of } \\
\text { infestation }\end{array}$ & $\begin{array}{c}\text { Colour of } \\
\text { aphids }\end{array}$ & $\begin{array}{c}\text { Locality } \\
\text { (altitude) }\end{array}$ & 2n & $\begin{array}{c}\text { Fig. } \\
\text { No. }\end{array}$ & $\begin{array}{c}\text { Idiogram } \\
\text { No. }\end{array}$ \\
\hline Rosa sp. & $14-6-90$ & Apical shoots & Green & $\begin{array}{l}\text { Shimla } \\
(1829 \mathrm{~m})\end{array}$ & 14 & 1 & 4 \\
Rosa sp. & $28-8-90$ & Leaves & Red & $\begin{array}{l}\text { Shimla } \\
(1829 \mathrm{~m})\end{array}$ & 18 & 2 & 5 \\
$\begin{array}{l}\text { Rubus ellipticus, } \\
\text { Smith }\end{array}$ & $21-7-90$ & Leaves & Green & $\begin{array}{l}\text { Shimla } \\
(1829 \mathrm{~m})\end{array}$ & 18 & 3 & 6 \\
\hline
\end{tabular}



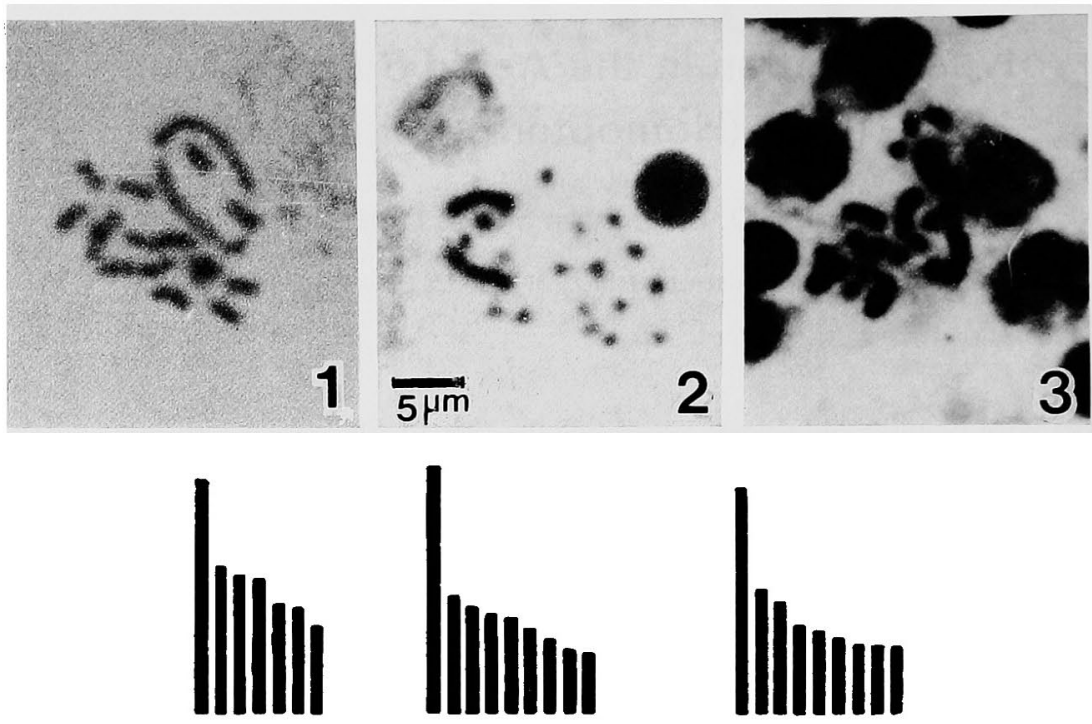

4

5

6

Figs. 1-6. Diploid chromosome numbers and idiograms of different populations of Sitobion rosaeiformis (Das). 1. $2 n=14$ in the population collected from Rosa sp. $2.2 n=18$ in the other population collected from Rosa sp. $3.2 \mathrm{n}=18$ in the population collected from Rubus ellipticus. 4. Idiogram of the population with $2 n=14$ from Rosa sp. 5. Idiogram of the population with

$2 n=18$ from Rosa sp. 6. Idiogram of the population with $2 n=18$ from Rubus ellipticus.

\section{Observations}

Aphid populations collected from Rosa sp. in summer (June) show $2 n=14$ (Fig. 1) and those collected from Rosa sp. and Rubus ellipticus during rainy season (July-August) revealed $2 n=18$ (Figs. 2, 3). The measurement of chromosomes of the population of these three samples show that the total complement lenght (TCL) is $24.93 \pm 0.04 \mu \mathrm{m}, 19.66 \pm 0.32 \mu \mathrm{m}$ and $25.66 \pm 0.17 \mu \mathrm{m}$, respectively (Table 2). In all these samples, there is one pair of long chromosomes while the rest of the chromosomes are small in size. This is reflected in the idiograms (Figs. 4, 5, 6) constructed from relative length data of chromosomes.

\section{Discussion}

Most of the Indian workers (See Raychaudhuri et al. 1980, Ghosh 1986) do not consider Sitobion and Macrosiphum as distinct genera. However, Blackman and Eastop (1984) treated these as two distinct genera and Sitobion has been distinguished from Macrosiphum by having less developed antennal tubercles and a more sclerotic dorsum bearing short hairs.

At present Sitobion genus is represented by about 75 species. In very few species of this genus, the diploid chromosome numbers are known which show clear variability in $2 \mathrm{n}$ i.e. 12 , 16 and 18 (Robinson and Chen 1969, Kuznetsova and Shaposhnikov 1973, Gut 1976, Blackman 1980). This aphid species has been recorded earlier on Rosa sp. from Himachal Pradesh (India). The collections made in the present study from this region have been found on Rubus ellipticus also. The populations collected from Rosa sp. during summer (June) and rainy (July-August) seasons revealed that $2 \mathrm{n}$ is 14 and 18 respectively in these two populations (Tables 1, 2). In case of the population collected from Rubus ellipticus $2 \mathrm{n}$ is 18 (Tables 1,2 ). 


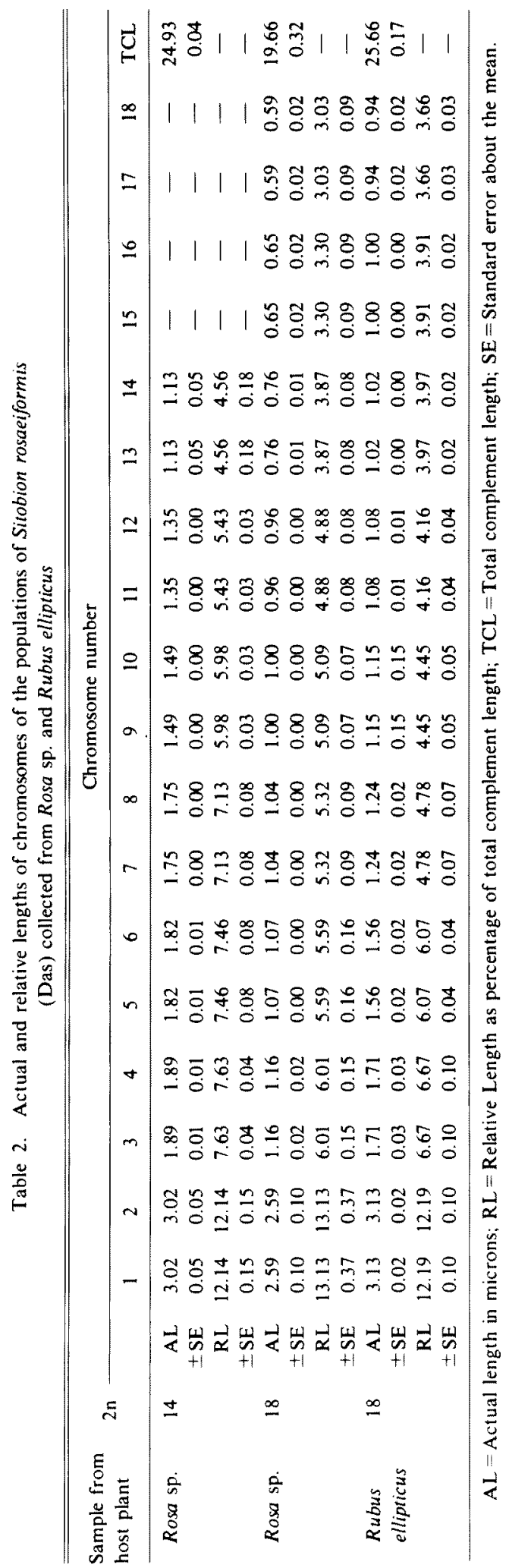


Earlier, Khuda-Bukhsh (1980) and Kurl and Misra (1983) reported 2n=18 in Macrosiphum rosaeformis (=Sitobion rosaeiformis). The total complement lengths $(24.93 \pm 0.04 \mu \mathrm{m}, 19.66 \pm$ $0.32 \mu \mathrm{m}, 25.66 \pm 0.17 \mu \mathrm{m}$ ) observed in these populations of Sitobion rosaeiformis in the present study (Table 2) are closer to that $(27.8 \mu \mathrm{m})$ reported by Khuda-Bukhsh (1980) and differ considerably from the one $(44.32 \mu \mathrm{m})$ reported by Kurl and Misra (1983) for Macrosiphum rosaeformis. The fact that these two genera have been considered distinct (Blackman and Eastop 1984), the materials worked out cytologically earlier from India (Khuda-Bukhsh 1980, Kurl and Misra 1983) need to be re-examined for specific taxonomic placement.

It is interesting to note that total complement lengths in the population with $2 \mathrm{n}=14$ from Rosa sp and in the population with $2 \mathrm{n}=18$ from $R$ ubus ellipticus are $24.93 \pm 0.04 \mu \mathrm{m}$ and 25.66 $\pm 0.17 \mu \mathrm{m}$, respectively (Table 2 ) which are approximately similar, whereas the population with $2 \mathrm{n}=18$ from Rosa sp. shows total complement length of $19.6 \pm 0.32 \mu \mathrm{m}$. These findings indicate that the differences in the genome size occur in different populations of this species and occurrence of higher number may be due to fragmentation which is accompanied by loss of genetic material. The idiogram prepared from the relative length data of these three populations revealed that the first pair is appreciably long in comparison to rest of the chromosomes. This long pair seems to be more resistant to fragmentation and is probably the sex chromosome pair. Sitobion rosaeiformis reported from other regions of the world is holocyclic (Blackman and Eastop 1984). Ghosh (1986) has recorded sexual forms of Macrosiphum rosaeformis from this region. The occurrence of sexuales indicates that this species must be holocyclic although no other details of its life cycle are available in literature from this region. If it is so, then this is a case of karyotype variation in a holocyclic aphid species. Such karyotype variation is earlier reported in holocyclic populations of Myzus persicae on Prunus persicae in Japan and Australia (Blackman 1980). Other aphid species in which karyotype variations have been studied are either anholocyclic like Rhopalosiphum maidis (Blackman et al. 1990) or are partially or completely anholocyclic like Myzus persicae (Blackman 1980).

The relationship between karyotype variation and association with host plant has been reported in Rhopalosiphum maidis (Brown and Blackman 1988). In this species $2 n=8$ is associated with samples from maize, sorghum and Johnson grass, whereas $2 n=10$ is associated with barley (Brown and Blackman 1988). Earlier, Chattopadhay et al. (1982) also observed differences in number and size of chromosomes in samples of $R$. maidis $(2 \mathrm{n}=8$ and 10$)$ collected from Triticum vulgare and Zea mays respectively.

In the present study it is quite evident that the variation in chromosome number and length exists even within the same species infesting the same host plant. Possibly the host plant and the season affect the genome size of aphids which generally reproduce parthenogenetically for greater part of the year. As no clear pattern of dissociation and translocation in karyotypes of these aphid samples could be observed, further studies are required to ascertain the exact mechanism involved in karyotype variation in this species.

\section{Summary}

Variation in karyotype of Sitobion rosaeiformis (Das) collected from two different hosts Rosa sp. and Rubus ellipticus has been reported in this paper. Surprisingly, the populations of this aphid species collected during rainy season on two different hosts possess $2 n=18$, whereas a population collected in summer on the former host shows $2 n=14$. These findings suggest that the host plant and the season possibly affect the genome size in aphids. 


\section{Acknowledgements}

The authors are thankful to the CAB International Institute of Entomology, London for help in identifying the aphid species. One of us (JD) is thankful to CSIR, New Delhi for a fellowship.

\section{References}

Blackman, R. L. 1971. Chromosomal abnormalities in an anholocyclic biotype of Myzus persicae (Sulzer). Experientia (Basel) 27: 704-706

- 1980. Chromosome numbers in the Aphididae and their taxonomic significance. Syst. Entomol. 5: 7-25.

- and Eastop, V. E. 1984. Aphids on the World's Crops. Wiley, New York.

- Halbert, S. E. and Carroll, T. W. 1990. Association between karyotype and host plant in corn leaf aphid (Homoptera: Aphididae) in the NorthWestern United States. Environ. Entomol. 19: 609-611.

Brown, P. A. and Blackman, R. L. 1988. Karyotype variation in the corn leaf aphid, Rhopalosiphum maidis species complex (Hemiptra: Aphididae) in relation to host plant and morphology. Bull. Entomol. Res., 78: $351-363$.

Chattopadhay, D., Das, P. L. and Raychaudhuri, D. 1982. Karyotype variation of Rhopalosiphum maidis. (Fitch) (Homoptera: Aphididae). Entomon 7: 441-446.

Ghosh, L. K. 1986. A conspectus of Aphididae (Homoptera) of Himachal Pradesh in NorthWest Himalaya India. Technical Monograph No. 16. Zoological Survey of India.

Gut, J. 1976. Chromosome numbers of parthenogenetic females of fifty-five species of Aphididae (Homoptera) new to cytology. Genetica 46: 279-285.

Khuda-Bukhsh, A. R. 1980. Karyotypic studies in six species of aphids (Homoptera: Aphididae) from the Garhwal Himalayas. Entomon 5: 247-250.

Kurl, S. P. and Misra, S. D. 1983. Karyological studies in two species of aphids. In: The Aphids (ed. B. K. Behura): 194-201.

Kuznetsova, V. G. and Shaposhnikov, G. Kh. 1973. The Chromosome numbers of the aphids (Homoptera Aphidinea) of the world fauna. Entomol. Rev. Washington 52: 78-96.

Raychaudhuri, D. N., Ghosh, M. R. and Basu, R. C. 1980. Subfamily Aphidinae: 47-278. In: Aphids of North East India and Bhutan (ed. D. N. Ray Chaudhuri), The Zoological Society, Calcutta: 1-521.

Robinson, A. G. and Chen, Y. H. 1969. Cytotaxonomy of Aphididae. Can. J. Zool., 47: 511-516. 